\title{
Liver Transplantation Beyond Milan Criteria
}

\author{
Vivek A Lingiah* ${ }^{1}$, Mumtaz Niazi ${ }^{1}$, Raquel Olivo ${ }^{1}$, Flavio Paterno ${ }^{2}$, James V Guarrera ${ }^{2}$ \\ and Nikolaos T Pyrsopoulos*1
}

\begin{abstract}
${ }^{1}$ Department of Medicine, Division of Gastroenterology and Hepatology, Rutgers University, New Jersey Medical School, Newark, NJ, USA; ${ }^{2}$ Department of Surgery, Division of Liver Transplantation and Hepatobiliary Surgery, Rutgers University, New Jersey Medical School, Newark, NJ, USA
\end{abstract}

\begin{abstract}
Hepatocellular carcinoma (HCC) is one of the leading causes of cancer-related death worldwide, being the fifth most common cancer and the third most common cause of cancer-related mortality. The incidence of HCC has been rising in the USA over the last 20 years. Liver transplantation is an optimal treatment option, as it eliminates HCC as well as the underlying liver disease. The Milan criteria ( 1 lesion greater than or equal to $2 \mathrm{~cm}$ and less than or equal to $5 \mathrm{~cm}$, or up to 3 lesions, each greater than or equal to $1 \mathrm{~cm}$ and less than or equal to $3 \mathrm{~cm}$ ) have been adopted by many transplant societies worldwide as the criteria to determine whether patients with HCC can move forward with liver transplantation. However, many believe that the Milan criteria may be too strict in regard to its size requirements for lesions. This has led to a number of expanded criteria for liver transplantation, concerning both overall size and number of lesions, as well as incorporation of other markers of tumor biology. Tumor markers, such as alphafetoprotein, can also be used to follow treatment of HCC and possibly exclude patients from transplant. HCC presenting beyond Milan criteria can also be down-staged with locoregional therapy. Monitoring response to locoregional therapy and longer wait times after locoregional therapy prior to transplant can serve as surrogate markers of tumor biology as well.
\end{abstract}

Citation of this article: Lingiah VA, Niazi M, Olivo R, Paterno F, Guarrera JV, Pyrsopoulos NT. Liver transplantation beyond Milan criteria. J Clin Transl Hepatol 2020;8(1):69-75. doi: $10.14218 /$ JCTH.2019.00050.

Keywords: Hepatocellular carcinoma; Liver transplantation; Cancer staging; Tumor burden; Alpha-fetoprotein.

Abbreviations: AFP, alpha-fetoprotein; BCLC, Barcelona Clinic Liver Cancer; HCC, hepatocellular carcinoma; LRT, locoregional therapy; LT, liver transplantation; MELD, Model for End-Stage Liver Disease; MMaT, Median MELD at Transplant; MRECIST, modified response evaluation criteria in solid tumors; OLT, orthotopic liver transplantation; RETREAT, risk estimation of tumor recurrence after transplant; TACE, trans-arterial chemoembolization; TNM, tumor-node-metastasis; TTV, total tumor volume; UCSF, University of California, San Francisco; UNOS, United Network for Organ Sharing.

Received: 7 October 2019; Revised: 4 February 2020; Accepted: 3 March 2020 *Correspondence to: Nikolaos T Pyrsopoulos, Gastroenterology and Hepatology, Rutgers University, New Jersey Medical School, MSB H-355, 185 S Orange Ave, Newark, NJ 07103, USA. Tel: +1-973-972-5252, Fax: +1-973-972-3144, E-mail: pyrsopni@njms.rutgers.edu; Vivek A Lingiah, Division of Gastroenterology and Hepatology, Rutgers University, New Jersey Medical School, MSB H-350, 185 S Orange Ave, Newark, NJ 07103, USA. Tel: +1-973-972-5252, Fax: +1-973-9723144, E-mail: lingiava@njms.rutgers.edu

\section{Introduction}

Hepatocellular carcinoma (HCC) is one of the leading causes of cancer-related death worldwide, being the fifth most common malignancy and the third most common cause of cancerrelated mortality. ${ }^{1,2}$ The incidence of HCC has been rising in the USA over the last 20 years and has been attributed to risk factors, such as chronic hepatitis $C$ infection, hepatitis B infection, heavy alcohol use, diabetes, and nonalcoholic fatty liver disease, among others. ${ }^{3}$ Recent data has shown that only $46 \%$ of HCC cases are diagnosed early on and most are unable to receive curative therapy. ${ }^{4}$ Currently, it is estimated that the median survival for untreated HCC is less than 1 year. $^{5}$

Surgical resection, orthotopic liver transplant (OLT), and ablative techniques are potentially the only curative options available for HCC. Liver transplant is an excellent therapeutic option for long-term survival in patients with HCC, as it eliminates both HCC and the underlying advanced liver disease. ${ }^{2}$ Initially, poor patient selection (advanced tumor burden, unclear tumor etiology) resulted in high rates of tumor recurrence post-transplant. ${ }^{6}$ This changed in 1996 when Mazzaferro and colleagues ${ }^{7}$ showed $75 \%$ 4-year survival rate and $83 \%$ recurrence-free survival rate, utilizing their now well-known Milan criteria. These criteria (one lesion greater than or equal to $2 \mathrm{~cm}$ and less than or equal to $5 \mathrm{~cm}$, or up to 3 lesions, each greater than or equal to $1 \mathrm{~cm}$ and less than or equal to $3 \mathrm{~cm}$, with no evidence of vascular invasion or extra-hepatic metastases) showed comparable survival outcomes compared to transplants performed on patients with cirrhosis but without HCC.

The Milan criteria have seen widespread approval and have been incorporated into the United Network for Organ Sharing (UNOS) criteria since 2002, for listing patients with HCC for liver transplant. UNOS is the private, non-profit group that handles the USA's organ transplant system, under contract with the US government. They manage the US transplant waiting list as well as the database that contains all the organ transplant data in the country. ${ }^{8}$ The Organ Procurement and Transplantation Network is the government workforce operating as a part of the Human Resources and Services Administration of the US Department of Health and Human Services. ${ }^{9}$ Currently in the United States, the model for endstage liver disease score exception points are granted to patients with HCC within Milan criteria or who were initially identified as outside the Milan criteria but successfully downstaged within the Milan.

However, many believe that the Milan criteria may be too strict in regard to its size requirements for lesions. 
Publications from around the world support the idea that patients with HCC beyond Milan criteria can be transplanted with reasonable post-transplant outcomes (Table 1, Fig. 1). Additionally, the Milan criteria have been criticized as very restrictive, as this system is based on tumor size and number, without taking tumor biology into account. ${ }^{10}$ This is where the concept of downstaging takes place, which is a process of applying locoregional therapy (LRT) to lesions currently outside of the accepted transplant criteria, to reduce tumor burden, meet transplant criteria, and get transplanted. Many studies have reported acceptable long-term liver transplant outcomes for patients with HCC beyond Milan criteria who were successfully down-staged to within Milan criteria by applying LRT to reduce the tumor burden.

The purpose of this article is to review the different staging criteria present beyond the Milan criteria, types of LRT used in downstaging, and other factors used in evaluating posttransplant recurrence risk.

\section{Other HCC transplant criteria used}

One of the most commonly used expanded HCC liver transplant criteria was published by Yao et al. ${ }^{11}$ in 2001, known as the University of California, San Francisco (UCSF) criteria. These criteria are defined as a single tumor less than or equal to $6.5 \mathrm{~cm}$, or up to 3 lesions with the largest lesion less than or equal to $4.5 \mathrm{~cm}$, with a total tumor diameter no greater than $8 \mathrm{~cm}$. In that study, patients transplanted for HCC within these criteria had 1- and 5-year survival rates of $90 \%$ and $75.2 \%$ respectively, compared to a 1 -year survival rate of $50 \%$ in patients who exceeded these criteria. ${ }^{11}$ These criteria were originally fashioned using explant HCC pathological data but were later validated in subsequent studies. In 2007 , the same group used the UCSF criteria prospectively in 168 patients with pretransplant imaging and showed 5 -year recurrence-free survival of $81 \%$, similar to Milan criteria, while being able to offer OLT to an extra $5-20 \%$ of patients with HCC not included by the Milan criteria. ${ }^{12}$

Duffy et al. ${ }^{13}$ from UCLA looked at liver transplants performed for HCC between 1984 and 2006. In their cohort of 467 patients, 173 were within Milan criteria, 185 within UCSF criteria, and 109 beyond UCSF. There were no significant differences in post-transplant survival rates between the Milan and UCSF criteria at 5 years, by pre-operative imaging (79\% vs. $64 \%, p=0.061$ ). Patients with tumors beyond UCSF criteria had 5 -year post-transplant survival of less than $50 \%$. Further studies conducted more recently have validated the UCSF criteria as having similar patient and tumor-free survival compared to the Milan criteria. ${ }^{14}$

In 2000, the Pittsburgh criteria were conceived - these criteria modified the tumor-node-metastasis (commonly known as TNM) classification and investigated such HCC characteristics as micro/macrovascular invasion, lobar distribution, tumor size, and lymph node involvement (all of which are independent predictors of tumor-free survival), as well as evidence of metastatic disease. Tumor number was not found to be a significant predictor. In this staging system, tumorfree survival is directly proportional to staging, and the likelihood of tumor recurrence in each stage is homogenous. ${ }^{15}$ These criteria were able to increase the indications for transplant (being able to transplant larger-sized lesions that would not meet Milan criteria).

Chen et al. ${ }^{16}$ showed in their study that the Pittsburgh criteria better predicted outcomes and prognosis than the traditional International Union against Cancer pTNM classification. In a later study, the Pittsburgh group applied Milan and UCSF criteria to a cohort of 393 patients who underwent OLT for HCC. Of the 248 patients within Milan criteria, 5-year

Table 1. Various extended criteria for hepatocellular carcinoma and liver transplantation

\begin{tabular}{|c|c|c|}
\hline Criteria & Description & $\begin{array}{l}\text { Tissue/biopsy } \\
\text { needed? }\end{array}$ \\
\hline Milan criteria & $\begin{array}{l}1 \text { lesion } \geq 2 \mathrm{~cm} \text { and } \leq 5 \mathrm{~cm} \text { OR up to } 3 \text { lesions, each } \geq 1 \mathrm{~cm} \text { and } \leq 3 \mathrm{~cm} \\
\text { No evidence of vascular invasion or extra-hepatic metastases }\end{array}$ & No \\
\hline UCSF criteria & $\begin{array}{l}1 \text { lesion } \leq 6.5 \mathrm{~cm} \text { OR up to } 3 \text { lesions with the largest lesion } \leq 4.5 \mathrm{~cm} \text {, with a total } \\
\text { tumor diameter } \leq 8 \mathrm{~cm}\end{array}$ & No \\
\hline Pittsburgh criteria & $\begin{array}{l}\text { Tumor number not a significant predictor } \\
\text { Modified TNM classification } \\
\text { Micro/macrovascular invasion } \\
\text { Lobar distribution } \\
\text { Tumor size } \\
\text { Lymph node involvement } \\
\text { Evidence of metastatic disease }\end{array}$ & Yes \\
\hline Hangzhou criteria & $\begin{array}{l}\text { Total tumor diameter could be: } \\
\begin{array}{l}\text { (1) } \leq 8 \mathrm{~cm} \text { OR } \\
\text { (2) }>8 \mathrm{~cm} \text {, with histopathologic grade } 1 \text { or } 2 \text {, and a preoperative alpha-fetoprotein } \\
\text { value of } \leq 400\end{array}\end{array}$ & Yes \\
\hline $\begin{array}{l}\text { Up-to-seven } \\
\text { criteria }\end{array}$ & $\begin{array}{l}7 \text { as total of the size of the largest lesion in } \mathrm{cm} \text { and number of lesions } \\
\text { No vascular invasion }\end{array}$ & Yes \\
\hline Toronto criteria & $\begin{array}{l}\text { No upper limit on size and number of lesions } \\
\text { No extra-hepatic metastases, evidence of venous or biliary tumor thrombus OR } \\
\text { cancer-related symptoms } \\
\text { All lesions beyond Milan criteria require a liver biopsy to evaluate for poor } \\
\text { differentiation, which is exclusionary }\end{array}$ & Yes \\
\hline
\end{tabular}




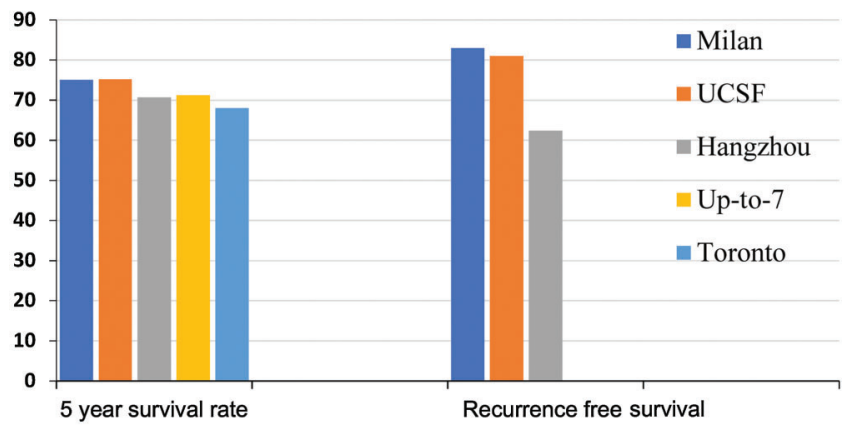

Fig. 1. Comparison of 5-year overall and recurrence-free survival rates between different transplant criteria.

patient survival and recurrence-free survival rates were $67.3 \%$ and $95.7 \%$. Of the 265 patients within UCSF criteria, the 5 -year patient survival and recurrence-free survival rates were $67 \%$ and $94.4 \% .{ }^{17}$ However, one of the main roadblocks to using these criteria is that information on vascular invasion and lymph node involvement is not easily obtained preoperatively, limiting its use.

In 2008, the Hangzhou criteria were established. These criteria dictated that the total tumor diameter could be either 1) less than or equal to $8 \mathrm{~cm}$ or 2) greater than $8 \mathrm{~cm}$, with histopathologic grade 1 or 2 (based on Edmonson criteria, which describe grade 1 as being well differentiated and grade 2 as being moderately differentiated) and a preoperative alphafetoprotein (AFP) $\leq 400$. Using these criteria, 5-year overall survival was $70.7 \%$ and recurrence-free survival was $62.4 \%$, similar to Milan criteria. However, with the Hangzhou criteria, an additional $37.5 \%$ of patients who would have been beyond Milan criteria were able to be transplanted, having favorable long-term survival outcomes. ${ }^{18}$ These criteria, however, rely on pretransplant lesional biopsies to estimate tumor differentiation. As the American Association for the Study of Liver Disease guidelines do not recommend routine biopsy of liver lesions, this would be more difficult to implement.

In 2009, Mazzafero and colleagues ${ }^{19}$ came up with the Upto-Seven criteria. These criteria proposed that HCC with 7 as the total of the size of the largest lesion in $\mathrm{cm}$ and number of lesions, without vascular invasion, could have survival outcomes as good as those within Milan criteria. Using a registry of 1556 patients who underwent OLT for HCC in 36 centers, 1112 had HCC beyond Milan criteria and 444 had HCC within Milan criteria. A total of 454 of the 1112 patients had microvascular invasion, and the 5-year survival of those outside Milan criteria was $53.6 \%$ compared to the $73.3 \% 5$-year survival for those within Milan criteria. In the 283 patients without microvascular invasion but who were within the Up-to-Seven criteria, 5-year overall survival was $71.2 \% .{ }^{19} \mathrm{~A}$ limitation to that study was that it utilized data from postoperative histology in making determinations on outcomes. This would not be available in the pretransplant setting. Other determinants of tumor biology (response to pretransplant treatment, AFP concentrations, etc.) were also not utilized. ${ }^{19}$ That being said, it was in this study that the 'Metro Ticket Calculator' was conceived, which can provide 3- and 5-year overall survival probabilities based on characteristics of the HCC lesion. The concept posits that the farther you travel (beyond Milan/established criteria), the greater the price (higher post-transplant mortality and $\mathrm{HCC}$ recurrence rates). ${ }^{10}$
In 2016, the Toronto extended criteria were published. These criteria have no upper limit on size and number of lesions, but exclude patients with extrahepatic metastases, evidence of venous or biliary tumor thrombus, or cancerrelated symptoms (weight loss $>10$ lbs or worsening performance status over 3 months). ${ }^{20}$ Most importantly, all patients with lesions beyond Milan criteria require a liver biopsy of the largest lesion to evaluate for poor differentiation, which would exclude patients as well. Prospective analysis was done comparing 138 patients meeting Milan criteria versus 105 patients beyond Milan criteria (72.4\% of which were beyond UCSF criteria) but within Toronto criteria; the 5 -year survival rates were not statistically different between the two groups (78\% vs. $68 \%$ ). AFP was also reviewed afterwards and values $>500$ at listing or at time of transplant were associated with worse outcomes, regardless of whether they were or were not within Milan criteria. ${ }^{20}$ These criteria are novel as they are more directly trying to measure tumor biology. However, some may have issue with a lesional biopsy, as there is an increased risk of tumor seeding.

\section{Biomarkers}

The previously mentioned extended criteria demonstrate that there is an increased desire for further information on tumor biology and surrogates of tumor biology when trying to determine transplant suitability. While histopathologic data of lesions can be helpful in determining presence of microvascular invasion or poorly differentiated HCC, these characteristics are difficult to obtain in the pretransplant setting. This limitation has led to an increased interest in identifying the best prognostic serologic biomarkers for HCC.

AFP is the most common prognostic biomarker studied in relation to HCC. It has been utilized by numerous centers and has been recently adopted by UNOS as a marker to exclude or include patients from transplant listing (Table 2). Hameed et al. ${ }^{21}$ investigated 211 patients who underwent OLT for $\mathrm{HCC}$ and were within Milan criteria based on imaging. There was a significant association between AFP levels and vascular invasion, starting at AFP level greater than $300 \mathrm{ng} / \mathrm{mL}$. AFP greater than $1000 \mathrm{ng} / \mathrm{mL}$ was noted to be the strongest pretransplant variable predicting vascular invasion, which was the only significant predictor of tumor recurrence. The 5year recurrence-free survival rate for patients with AFP greater than $1000 \mathrm{ng} / \mathrm{mL}$ was $52.7 \%$ compared to $80.3 \%$ in those with AFP less than $1000 \mathrm{ng} / \mathrm{mL} .{ }^{21}$ Utilizing this as an exclusion in the trial would have excluded $4.7 \%$ of patients and decreased the rate of HCC recurrence by $20 \%$. Using a lower cut-off of AFP greater than $400 \mathrm{ng} / \mathrm{mL}$ would have doubled the number of patients excluded (to around $9 \%$ ) but with only an extra $6 \% \mathrm{HCC}$ recurrence reduction. ${ }^{21}$

Duvoux et al. ${ }^{22}$ were able to demonstrate that increasing AFP levels at time of listing were related to worse 5-year recurrence and survival rates. When patients were divided into groups based on AFP less than $100 \mathrm{ng} / \mathrm{mL}$, between $100-1000 \mathrm{ng} / \mathrm{mL}$, and greater than $1000 \mathrm{ng} / \mathrm{mL}$, there were statistically significant different 5-year recurrence and overall survival rates $(16.2 \%$ and $67.5 \%$ vs. $26.8 \%$ and $51.1 \%$ vs. $53.0 \%$ and $39.1 \%, p<0.001) .{ }^{22}$ In particular, according to their model, even subsets of patients exceeding Milan criteria with one to three lesions and a largest lesion size of $6 \mathrm{~cm}$ or with four or more lesions with maximum tumor diameter of 3 $\mathrm{cm}$ could be considered eligible for OLT if their AFP was less than $100 \mathrm{ng} / \mathrm{mL}$. Conversely, the model identified patients 
Lingiah V.A. et al: Liver transplantation beyond Milan criteria

Table 2. The 5-year recurrence, recurrence-free survival and overall survival rates based on pretransplant alpha-fetoprotein level

\begin{tabular}{lllll}
\hline $\begin{array}{l}\text { Study, First } \\
\text { author }\end{array}$ & Alpha-fetoprotein level & $\begin{array}{l}5 \text {-year recurrence } \\
\text { rate, } \%\end{array}$ & $\begin{array}{l}\text { 5-year recurrence-free } \\
\text { survival rate, \% }\end{array}$ & $\begin{array}{l}\text { 5-year overall } \\
\text { survival rate, } \%\end{array}$ \\
\hline Hameed & $>1000 \mathrm{ng} / \mathrm{mL}$ & - & 52.7 & - \\
& $<1000 \mathrm{ng} / \mathrm{mL}$ & - & 80.3 & - \\
Duvoux & $<100 \mathrm{ng} / \mathrm{mL}$ & 16.2 & - & 67.5 \\
& $100-1000 \mathrm{ng} / \mathrm{mL}$ & 26.8 & - & 51.1 \\
Hangzhou & $>1000 \mathrm{ng} / \mathrm{mL}$ & 53 & - & 39.1 \\
Lai & $\leq 400 \mathrm{ng} / \mathrm{mL}$ & - & 74.4 & -70.7 \\
Toso & $\leq 400 \mathrm{ng} / \mathrm{mL}$ and/or tumor & 4.9 & - & - \\
& $\leq 400 \mathrm{ng} / \mathrm{mL}$ and TTV & - & & 74.6 (4-year) \\
\hline
\end{tabular}

within Milan criteria but with AFP greater than $1000 \mathrm{ng} / \mathrm{mL}$ with high recurrence risk and significantly reduced survival. ${ }^{22}$

However, the optimal AFP value for defining patients at higher risk for HCC recurrence has not been found. The Hangzhou criteria previously mentioned utilization of an AFP cut-off of up to $400 \mathrm{ng} / \mathrm{mL}$ and were able to obtain a 5-year overall survival rate of $70.7 \%$ in patients meeting their criteria. ${ }^{18}$ Lai et al. ${ }^{23}$ reviewed 158 patients undergoing OLT for HCC and noted that patients with the combination of AFP up to $400 \mathrm{ng} / \mathrm{mL}$ and total tumor diameter no greater than 8 $\mathrm{cm}$ had a 5-year recurrence-free survival of $74.4 \%$, similar to Milan and UCSF criteria, while this approach was able to increase the number of transplant candidates. Toso et al. ${ }^{24}$ used similar parameters with their study, looking at total tumor volume (referred to here as TTV; being no greater than $115 \mathrm{~cm}^{3}$ ) and AFP no greater than $400 \mathrm{ng} / \mathrm{mL}$. In their prospective study of 166 patients transplanted for HCC, 134 were within Milan and 32 were beyond Milan but within TTV/ AFP criteria; the 4-year overall survival rates for the Milan and TTV/AFP groups were similar at $78.7 \%$ vs. $74.6 \%$. Some studies have even recommended an AFP less than $100 \mathrm{ng} / \mathrm{mL}$ as an upper limit. Grat et al. ${ }^{25}$ performed a study evaluating 121 patients transplanted for HCC and demonstrated that increasing AFP had a nearly linear association with increased risk of HCC recurrence in patients transplanted within UCSF and Up-to-Seven criteria. Patients transplanted under UCSF and within AFP limits had better 5-year recurrence-free survival than those within UCSF but not within the AFP limit ( $100 \%$ vs. $69 \%$ ). This trend was also seen in those meeting the Up-to-Seven criteria (100\% vs. $71.9 \%$ ).

Recent publications have not only been investigating just a static AFP prior to OLT but the trend of AFP in patients awaiting OLT. This AFP 'slope' has been thought to be more reflective of the dynamic nature of tumor biology than just a single value. Giard et al. ${ }^{26}$ recently looked at 336 patients undergoing OLT for HCC who were within Milan criteria. Nearly all (98\%) of the patients had LRT at some time prior to transplant and the AFP slope was estimated by the AFP values during this pretransplant period. An AFP slope increase greater than $7.5 \mathrm{ng} / \mathrm{mL} / \mathrm{month}$ despite LRT was significantly associated with post-transplant HCC recurrence (3-time increasing risk compared to those with a decreasing AFP slope) and microvascular invasion. ${ }^{26}$

The current UNOS HCC model for end-stage liver disease exception criteria take into account a candidate's AFP. Candidates applying for standardized MELD exception for within
Milan criteria HCC must have an AFP less than or equal to 1000 $\mathrm{ng} / \mathrm{mL}$. Candidates with AFP greater than $1000 \mathrm{ng} / \mathrm{mL}$ can undergo LRT, and if the AFP decreases to less than $500 \mathrm{ng} / \mathrm{mL}$, then the candidate can be qualified for a standardized MELD exception (as long as the AFP remains $<500 \mathrm{ng} / \mathrm{mL}$ ). Patients with AFP greater than $500 \mathrm{ng} / \mathrm{mL}$ after LRT need to apply to the national liver review board to receive MELD exception points. ${ }^{27}$

\section{Downstaging}

Besides using extended criteria to transplant patients with HCC beyond Milan criteria, patients might undergo therapy until the tumor burden will be within the Milan criteria. The term, 'downstaging', refers to the use of LRT applied in order to decrease the tumor burden until it meets suitable criteria for OLT (usually Milan criteria). ${ }^{10}$ One of the advantages of this method is that tumor biology can be assessed based on tumor behavior over a period of time. Good response to downstaging has often been linked to the presence of histologic markers of good prognosis in the treated HCC (lack of microvascular invasion, low tumor grading, lack of satellite lesions), similar to patients being transplanted within Milan criteria at presentation. ${ }^{28}$ In the USA, UNOS policy now requires a 6 month waiting period prior to granting HCC MELD exception points, so that tumor biology and response to LRT can be assessed. ${ }^{27}$

Yao et al. ${ }^{29}$ showed in 2015 that patients beyond Milan criteria undergoing downstaging to within Milan criteria for HCC prior to OLT had similar 5-year post-transplant survival and recurrence-free probabilities compared to patients within Milan criteria (T2 lesion) without downstaging ( $77.8 \%$ and $90.8 \%$ vs. $81 \%$ and $88 \%$ ). Even when assessing response via 5-year intention-to-treat survival rate, there was no difference between the downstaging and T2 groups (56.1\% vs. $63.3 \%$ ). Similar post-transplant outcomes have been shown in other downstaging studies as well. ${ }^{5,30}$ Current UNOS policy includes a downstaging protocol to allow patients to obtain HCC MELD exception points if specific criteria are met (Fig. 2). ${ }^{27}$

The main options for LRT include ablative techniques (radiofrequency ablation or microwave ablation), transarterial chemoembolization (TACE), or trans-arterial radioembolization. The decision as to what type of LRT should be used depends on the degree of tumor burden, liver function, and location of the tumor. ${ }^{10}$ The most commonly used staging system for HCC is the Barcelona Clinic Liver Cancer 


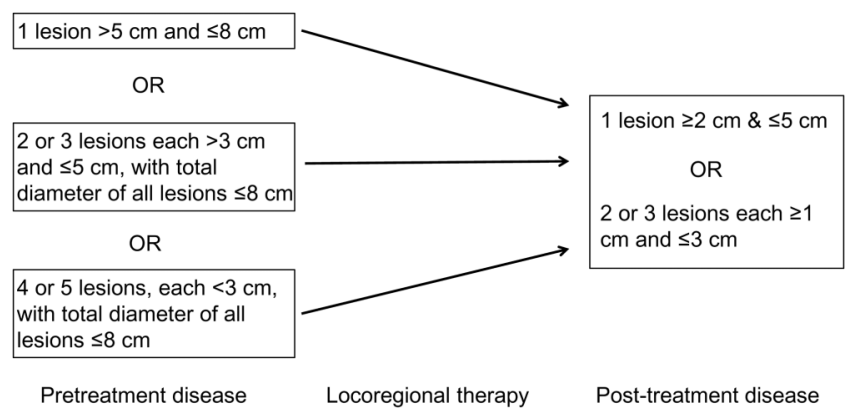

Fig. 2. Downstaging protocol according to UNOS policy.

Candidates can be eligible for model for end-stage liver disease exception points if their pretreatment disease meets one of the criteria in the left column. Once undergoing locoregional therapy, if the candidate's post-treatment disease meets T2 criteria (an option in the right column), they are eligible for a standardized model for end-stage liver disease exception.

(commonly known as the BCLC) staging system. This system evaluates tumor burden, liver function, as well as patient performance status when stratifying patients into different categories. Given that patients being down-staged have advanced tumor burden, based on BCLC staging, TACE is usually utilized most often, followed by trans-arterial radioembolization and ablative techniques. ${ }^{2}$

Since it has the best quality of evidence, TACE is the recommended treatment option for large or multifocal HCC without evidence of vascular invasion or extrahepatic metastasis (BCLC stage $B$, intermediate). ${ }^{31}$ Conventional TACE involves arterial catheter delivery of chemotherapy (usually doxorubicin or cisplatin) via lipiodol emulsion followed by vascular embolization of tumor-feeding vessels. The combination of cytotoxic and ischemic injury tends to be significant as these lesions are usually fed entirely by arterial flow, as opposed to liver parenchyma that receives most of its blood flow via the portal system. ${ }^{28}$ Patients with poor hepatic function (total bilirubin $>2 \mathrm{mg} / \mathrm{dL}$ ) or tumor burden greater than $50 \%$ of liver volume have higher risk for decompensation after TACE. ${ }^{28}$ The advent of super-selective TACE, done to minimize ischemic injury to nontumor liver tissue while still inducing tumor necrosis, can mitigate some of these risks. ${ }^{32}$

Trans-arterial radioembolization is another treatment modality for HCC. With this modality, microspheres containing Yttrium-90 are infused into the hepatic artery and are preferentially delivered to the tumor area, where they emit high-energy, low-penetration radiation to the tumor. Because of the small size of the microspheres, trans-arterial radioembolization can be used in portal vein thrombus. ${ }^{28}$

Ablative techniques have also been used with downstaging, though these are usually used in concert with other forms of LRT. These range from percutaneous ethanol injection to radiofrequency or microwave ablation. In radiofrequency ablation, cell death is attained by frictional heat using high frequency alternating current, this heat producing coagulation necrosis. ${ }^{28}$ Location of the lesion is important when considering radiofrequency ablation, as lesions near blood vessels may not be treated appropriately due to a heat sink effect (impaired heating of tumor cells because of 'cooler' blood flow near the lesion). Lesions treated are usually no larger than $3 \mathrm{~cm}$, as the ablative zone produced with radiofrequency ablation results in reduced tumor ablation in lesions larger than $3 \mathrm{~cm} .{ }^{2}$ Microwave ablation uses electromagnetic energy to heat tissue and is less prone to the heat sink effect, allowing treatment of lesions near large blood vessels. ${ }^{28}$

\section{Response to LRT and wait times}

The response of HCC to different modalities of LRT is an important surrogate marker for survival, as well as a measure of tumor biology. The modified Response Evaluation Criteria in Solid Tumors (mRECIST) criteria were developed as a method for measuring treatment response based on tumor shrinkage. These criteria distinguish response into four categories complete response (disappearance of arterial enhancement in tumor(s)), partial response (at least $30 \%$ reduction in sum of diameters of viable tumor compared to baseline), stable disease (not meeting partial response or progressive disease criteria), and progressive disease (an increase of at least $20 \%$ in sum of the diameters of viable tumor compared to baseline, or the appearance of new lesions). ${ }^{33}$ Gillmore et al. ${ }^{34}$ performed a study looking at 83 patients with HCC undergoing TACE with follow-up imaging done after a median of 64 days. They found overall and target lesion response of $57 \%$ and $73 \%$ based on mRECIST results, with a significant association between survival and overall (complete or partial) mRECIST response in the form of a $42 \%$ risk reduction. Bargellini et $a l .{ }^{35}$ presented a study of 33 patients with HCC beyond Milan criteria who underwent OLT after treatment with TACE. Tumor response was reviewed by CT scan at 1 month after intervention based on mRECIST criteria. The 5-year overall survival rate was significantly better in patients with complete response $(94.4 \%)$ compared to partial response $(45.4 \%)$ and stable disease (50\%). These significant differences were similarly seen with 5-year recurrence-free rates (94.4\% vs. $46.7 \%$ and $50 \%$, respectively). Another study assessed patients undergoing OLT for HCC after TACE (both within and beyond Milan criteria), with treatment response assessed using mRECIST. That study showed that the 5-year recurrence rate was $5.3 \%$ in complete and partial responders compared to $17.6 \%$ in those with stable or progressive disease. ${ }^{36}$

Along with response to LRT, the waiting time while listed for liver transplant can be used to further assess tumor biology and identify aggressive HCC. Halazun et al. ${ }^{37}$ showed that patients with HCC receiving OLT in regions with shorter wait times (median of 1.6 months) had significantly higher posttransplant mortality than patients transplanted in regions with longer wait times (median 7.6 months), with 5-year survival rates of $67 \%$ versus $75 \%$, respectively. The concept of 'ablate and wait' to assess tumor biology over time has been shown to have merit in other studies, with the most current UNOS policy requiring a 6 month waiting period for patients listed with HCC prior to receiving MELD exception points. ${ }^{27,38}$

The policies in regard to UNOS MELD exceptions for HCC have been an evolving field. Up until recently, patients were granted a MELD exception of 28 points after showing stable within-Milan criteria HCC for 6 months from listing (with an AFP $\leq 1000 \mathrm{ng} / \mathrm{mL}$ ). Escalating MELD exception points could be accrued every 3 months, with a cap of 34. Since May 2019, however, new policies have been implemented, where patients receive exception points equal to the median MELD at transplant (MMaT) -3 . The median MELD at transplant refers to the median of MELD scores at the moment of transplant of all recipients 12 years and older transplanted in hospitals within 250 nautical miles around the listing 
Table 3. RETREAT score components and scoring criteria breakdown

\begin{tabular}{lll}
\hline Characteristic & Range of values & RETREAT points \\
\hline Alpha-fetoprotein at transplant in $\mathrm{ng} / \mathrm{mL}$ & $0-20$ & 0 \\
& $21-99$ & 1 \\
& $100-999$ & 2 \\
Microvascular invasion & $>1000$ & 3 \\
& Absent & 0 \\
Largest active tumor length $(\mathrm{cm})+$ number of active tumors & 2 \\
& 0 & 2 \\
& $1.1-4.9$ & 0 \\
& $5-9.9$ & 1 \\
\hline
\end{tabular}

hospital in the last year. ${ }^{27}$ This change was made to make sure that a candidate's assigned score was more proportional to their needs and that candidates who relied on their native MELD were not disadvantaged. This was also done to ensure that MELD exception points for HCC had a similar impact on transplantation in different parts of the country, each with unique median MELDs at transplant. ${ }^{27,39}$

\section{Post-transplant recurrence}

One of the major fears after liver transplant for HCC is tumor recurrence, which has been noted to occur in $8-20 \%$ of transplanted patients. HCC recurrence usually occurs within 2 years after transplant, with a median survival of around 1 year after diagnosis. ${ }^{40}$ While many elements have been linked to tumor recurrence post-transplantation, there are few standardized risk scores formed to ascertain a transplant recipient's chances of HCC recurrence. After successful OLT in patients with HCC, further information can be obtained based on the explant pathology.

The Risk Estimation of Tumor REcurrence After Transplant (RETREAT) is a validated prognostic score to help predict post-transplant HCC recurrence, detect patients who can be assisted by adjuvant therapy, and aid in defining posttransplant HCC surveillance schedules. When reviewing characteristics significant for HCC recurrence in 721 patients with HCC within Milan criteria, three variables were noted to be independently associated with HCC recurrence. These included 1) tumor burden of the explant liver (total of largest viable tumor diameter and the number of viable tumors of explanted liver), 2) evidence of microvascular invasion, and 3) AFP at time of transplant. The RETREAT score was derived from these variables, with point values being assigned to each of the criteria and with scores ranging from 0-8 (higher scores denoting higher risk of recurrence) (Table 3). A RETREAT score of 0 predicted 1 - and 5-year HCC recurrence rates of $1 \%$ and $2.9 \%$, whereas RETREAT scores of 5 or more were associated with 1- and 5-year $\mathrm{HCC}$ recurrence rates of $39.3 \%$ and $75.2 \%$ (C-statistic of $0.77,95 \%$ confidence interval of $0.71-0.82$ ). This scoring system was validated in another cohort of 340 patients, with a C-statistic of 0.82 ( $95 \%$ confidence interval of $0.77-0.86) .{ }^{41}$

\section{Conclusions}

HCC is an ever-growing entity and is becoming a more common etiology to pursue orthotopic liver transplantation. Successful outcomes for transplantation due to HCC should have 5-year survival rates similar to those receiving liver transplant for non-HCC related liver disease. While the Milan criteria have provided good, stable post-transplant survival and recurrence-free outcomes, there appear to be other expanded criteria that have been able to provide similar outcomes while opening the pathway of transplant to a larger cohort of patients. The majority of these criteria, however, require lesional tissue/histology to comment on markers of tumor biology, like microvascular invasion or poor tumor differentiation. Downstaging of HCC to within Milan criteria is the alternative option. Surrogates of tumor biology can be assessed with this approach, such as response to LRT and increased wait times after LRT before transplant. AFP level or the AFP slope in producers can be another option to predict those with higher chances of recurrence and can be used in patient selection for transplant. These methods can be considered to choose optimal transplant candidates and increase the number of patients who liver transplantation can safely be offered to.

\section{Funding}

None to declare.

\section{Conflict of interest}

Nikolaos T Pyrsopoulos is a recipient of research grants from Gilead, Abbvie, Merck and Roche. The other authors have no conflict of interests related to this publication.

\section{Author contributions}

Reviewed the literature, performed the majority of the writing, and prepared the figures and tables (VAL), designed, co-authored and revised the manuscript (NTP), revised the manuscript (MN, RO, FP, JVG). 


\section{References}

[1] Ferlay J, Soerjomataram I, Dikshit R, Eser S, Mathers C, Rebelo M, et al. Cancer incidence and mortality worldwide: sources, methods and major patterns in GLOBOCAN 2012. Int J Cancer 2015;136:E359-E386. doi: 10. 1002/ijc. 29210.

[2] Marrero JA, Kulik LM, Sirlin CB, Zhu AX, Finn RS, Abecassis MM, et al. Diagnosis, staging, and management of hepatocellular carcinoma: 2018 practice guidance by the American association for the study of liver diseases. Hepatology 2018;68:723-750. doi: 10.1002/hep.29913.

[3] Kulik L, El-Serag HB. Epidemiology and management of hepatocellular carcinoma. Gastroenterology 2019;156:477-491.e1. doi: 10.1053/j.gastro. 2018.08.065.

[4] Singal AG, El-Serag HB. Hepatocellular carcinoma from epidemiology to prevention: Translating knowledge into practice. Clin Gastroenterol Hepatol 2015;13:2140-2151. doi: 10.1016/j.cgh.2015.08.014.

[5] Kim Y, Stahl CC, Makramalla A, Olowokure OO, Ristagno RL, Dhar VK, et al. Downstaging therapy followed by liver transplantation for hepatocellular carcinoma beyond Milan criteria. Surgery 2017;162:1250-1258. doi: 10. 1016/j.surg.2017.08.007.

[6] Iwatsuki S, Gordon RD, Shaw BW Jr, Starzl TE. Role of liver transplantation in cancer therapy. Ann Surg 1985;202:401-407. doi: 10.1097/00000658198510000-00001.

[7] Mazzaferro V, Regalia E, Doci R, Andreola S, Pulvirenti A, Bozzetti F, et al. Liver transplantation for the treatment of small hepatocellular carcinomas in patients with cirrhosis. N Engl J Med 1996;334:693-699. doi: 10 . 1056/NEJM199603143341104.

[8] What is UNOS? | About United Network for Organ Sharing. Available from: https://unos.org/about/.

[9] Organ Procurement and Transplantation Network. About the OPTN. Available from: https://optn.transplant.hrsa.gov/governance/about-the-optn.

[10] Rudnick SR, Russo MW. Liver transplantation beyond or downstaging within the Milan criteria for hepatocellular carcinoma. Expert Rev Gastroenterol Hepatol 2018;12:265-275. doi: 10.1080/17474124.2018.1417035.

[11] Yao FY, Ferrell L, Bass NM, Watson J], Bacchetti P, Venook A, et al. Liver transplantation for hepatocellular carcinoma: expansion of the tumor size limits does not adversely impact survival. Hepatology 2001;33:13941403. doi: 10.1053/jhep.2001.24563

[12] Yao FY, Xiao L, Bass NM, Kerlan R, Ascher NL, Roberts JP. Liver transplantation for hepatocellular carcinoma: validation of the UCSF-expanded criteria based on preoperative imaging. Am J Transplant 2007;7:2587-2596. doi: 10.1111/j.1600-6143.2007.01965.x.

[13] Duffy JP, Vardanian A, Benjamin E, Watson M, Farmer DG, Ghobrial RM, et al. Liver transplantation criteria for hepatocellular carcinoma should be expanded: a 22-year experience with 467 patients at UCLA. Ann Surg 2007;246:502-511. doi: 10.1097/SLA.0b013e318148c704.

[14] Abdelfattah MR, Elsiesy H, Al-Manea H, Broering DC. Liver transplantation for hepatocellular carcinoma within the Milan criteria versus the University of California San Francisco criteria: a comparative study. Eur J Gastroenterol Hepatol 2018;30:398-403. doi: 10.1097/MEG.0000000000001044.

[15] Marsh JW, Dvorchik I, Bonham CA, Iwatsuki S. Is the pathologic TNM staging system for patients with hepatoma predictive of outcome? Cancer $2000 ; 88$ : 538-543.

[16] Chen J, Xu X, Ling Q, Wu J, Zheng SS. Role of Pittsburgh modified TNM criteria in prognosis prediction of liver transplantation for hepatocellular carcinoma. Chin Med J (Engl) 2007;120:2200-2203.

[17] Marsh JW, Dvorchik I. Liver organ allocation for hepatocellular carcinoma: are we sure? Liver Transpl 2003;9:693-696. doi: 10.1053/jlts.2003.50086.

[18] Zheng SS, Xu X, Wu J, Chen J, Wang WL, Zhang M, et al. Liver transplantation for hepatocellular carcinoma: Hangzhou experiences. Transplantation 2008; 85:1726-1732. doi: 10.1097/TP.0b013e31816b67e4.

[19] Mazzaferro V, Llovet JM, Miceli R, Bhoori S, Schiavo M, Mariani L, et al. Predicting survival after liver transplantation in patients with hepatocellular carcinoma beyond the Milan criteria: a retrospective, exploratory analysis. Lancet Oncol 2009;10:35-43. doi: 10.1016/S1470-2045(08)70284-5.

[20] Sapisochin G, Goldaracena N, Laurence JM, Dib M, Barbas A, Ghanekar A, et al. The extended Toronto criteria for liver transplantation in patients with hepatocellular carcinoma: A prospective validation study. Hepatology 2016; 64:2077-2088. doi: 10.1002/hep.28643.

[21] Hameed B, Mehta N, Sapisochin G, Roberts JP, Yao FY. Alpha-fetoprotein level $>1000 \mathrm{ng} / \mathrm{mL}$ as an exclusion criterion for liver transplantation in patients with hepatocellular carcinoma meeting the Milan criteria. Liver Transpl 2014; 20:945-951. doi: 10.1002/It.23904.
[22] Duvoux C, Roudot-Thoraval F, Decaens T, Pessione F, Badran H, Piardi T, et al. Liver transplantation for hepatocellular carcinoma: a model including $\alpha$-fetoprotein improves the performance of Milan criteria. Gastroenterology 2012; 143:986-994.e3. doi: 10.1053/j.gastro.2012.05.052.

[23] Lai Q, Avolio AW, Manzia TM, Sorge R, Agnes S, Tisone G, Combination of biological and morphological parameters for the selection of patients with hepatocellular carcinoma waiting for liver transplantation. Clin Transplant 2012;26:E125-E131. doi: 10.1111/j.1399-0012.2011.01572.x.

[24] Toso C, Meeberg G, Hernandez-Alejandro R, Dufour JF, Marotta P, Majno P, et al. Total tumor volume and alpha-fetoprotein for selection of transplant candidates with hepatocellular carcinoma: A prospective validation. Hepatology 2015;62:158-165. doi: 10.1002/hep.27787.

[25] Grąt M, Kornasiewicz O, Lewandowski Z, Hołówko W, Grąt K, Kobryń K, et al. Combination of morphologic criteria and $\alpha$-fetoprotein in selection of patients with hepatocellular carcinoma for liver transplantation minimizes the problem of posttransplant tumor recurrence. World J Surg 2014;38:26982707. doi: 10.1007/s00268-014-2647-3.

[26] Giard JM, Mehta N, Dodge JL, Roberts JP, Yao FY. Alpha-fetoprotein slope $>7.5 \mathrm{ng} / \mathrm{ml}$ per month predicts microvascular invasion and tumor recurrence after liver transplantation for hepatocellular carcinoma. Transplantation 2018;102:816-822. doi: 10.1097/TP.0000000000002094.

[27] OPTN Policies. Available from: https://optn.transplant.hrsa.gov/media/1200/optn_policies.pdf.

[28] EASL Clinical Practice Guidelines: Management of hepatocellular carcinoma. J. Hepatol 2018;69:182-236. doi: 10.1016/j.jhep.2018.03.019.

[29] Yao FY, Mehta N, Flemming J, Dodge J, Hameed B, Fix O, et al. Downstaging of hepatocellular cancer before liver transplant: long-term outcome compared to tumors within Milan criteria. Hepatology 2015;61:1968-1977. doi: 10.1002/hep.27752.

[30] Ravaioli M, Grazi GL, Piscaglia F, Trevisani F, Cescon M, Ercolani G, et al. Liver transplantation for hepatocellular carcinoma: results of down-staging in patients initially outside the Milan selection criteria. Am J Transplant 2008; 8:2547-2557. doi: 10.1111/j.1600-6143.2008.02409.x

[31] Sieghart W, Hucke F, Peck-Radosavljevic M. Transarterial chemoembolization: modalities, indication, and patient selection. J Hepatol 2015;62: 1187-1195. doi: 10.1016/j.jhep.2015.02.010.

[32] Bryce K, Tsochatzis EA. Downstaging for hepatocellular cancer: harm or benefit? Transl Gastroenterol Hepatol 2017;2:106. doi: 10.21037/tgh. 2017.11.18.

[33] Lencioni R, Llovet JM. Modified RECIST (mRECIST) assessment for hepatocellular carcinoma. Semin Liver Dis 2010;30:52-60. doi: 10.1055/s-00301247132.

[34] Gillmore R, Stuart S, Kirkwood A, Hameeduddin A, Woodward N, Burroughs $A K$, et al. EASL and mRECIST responses are independent prognostic factors for survival in hepatocellular cancer patients treated with transarterial embolization. J Hepatol 2011;55:1309-1316. doi: 10.1016/j.jhep.2011.03.007.

[35] Bargellini I, Vignali C, Cioni R, Petruzzi P, Cicorelli A, Campani D, et al. Hepatocellular carcinoma: CT for tumor response after transarterial chemoembolization in patients exceeding Milan criteria-selection parameter for liver transplantation. Radiology 2010;255:289-300. doi: 10.1148/radiol. 09090927.

[36] Kim DJ, Clark PJ, Heimbach J, Rosen C, Sanchez W, Watt K, et al. Recurrence of hepatocellular carcinoma: importance of mRECIST response to chemoembolization and tumor size. Am J Transplant 2014;14:1383-1390. doi: 10.1111/ajt.12684

[37] Halazun KJ, Patzer RE, Rana AA, Verna EC, Griesemer AD, Parsons RF, et al. Standing the test of time: outcomes of a decade of prioritizing patients with hepatocellular carcinoma, results of the UNOS natural geographic experiment. Hepatology 2014;60:1957-1962. doi: 10.1002/hep.27272.

[38] Roberts JP, Venook A, Kerlan R, Yao F. Hepatocellular carcinoma: Ablate and wait versus rapid transplantation. Liver Transpl 2010;16:925-929. doi: 10. $1002 /$ It.22103.

[39] National Liver Review Board (NLRB) Frequently asked questions for candidates and caregivers. Available from: https://optn.transplant.hrsa.gov/media/2797/201901_nlrb_faq_patient.pdf.

[40] Clavien PA, Lesurtel M, Bossuyt PM, Gores GJ, Langer B, Perrier A. Recommendations for liver transplantation for hepatocellular carcinoma: an international consensus conference report. Lancet Oncol 2012;13:e11-e22. doi: 10.1016/S1470-2045(11)70175-9.

[41] Mehta N, Heimbach J, Harnois DM, Sapisochin G, Dodge JL, Lee D, et al. Validation of a risk estimation of tumor recurrence after transplant (RETREAT) score for hepatocellular carcinoma recurrence after liver transplant. JAMA Oncol 2017;3:493-500. doi: 10.1001/jamaoncol.2016.5116. 